\title{
Estimating dispersal distance in the deep sea: challenges and applications to marine reserves
}

\author{
Ana Hilário ${ }^{1}$, Anna Metaxas ${ }^{2 *}$, Sylvie M. Gaudron ${ }^{3}$, Kerry L. Howell ${ }^{4}$, Annie Mercier ${ }^{5}$, \\ Nélia C. Mestre ${ }^{6}$, Rebecca E. Ross ${ }^{4}$, Andreas M. Thurnherr ${ }^{7}$ and Craig Young ${ }^{8}$ \\ ${ }^{1}$ Departamento de Biologia \& Centre for Environmental and Marine Studies (CESAM), Universidade de Aveiro, Aveiro, Portugal \\ 2 Department of Oceanography, Dalhousie University, Halifax, NS, Canada \\ ${ }^{3}$ UMR8187 Laboratoire d'Océanologie et de Géosciences, Station Marine de Wimereux, Wimereux, France \\ ${ }^{4}$ Marine Biology and Ecology Research Centre, Marine Institute, Plymouth University, Plymouth, UK \\ ${ }^{5}$ Department of Ocean Sciences, Memorial University, St. John's, NL, Canada \\ ${ }^{6}$ Centro de Investigação Marinha e Ambiental, Universidade do Algarve, Faro, Portugal \\ ${ }^{7}$ Lamont-Doherty Earth Observatory, The Earth Institute of Columbia University, Palisades, NY, USA \\ ${ }^{8}$ Oregon Institute of Marine Biology, University of Oregon, Charleston, OR, USA
}

\section{Edited by:}

Cinzia Corinaldesi, Marche

Polytechnic University, Italy

Reviewed by:

Daniela Zeppilli, Institut Français de Recherche pour l'Exploitation de la Mer, France

Lisa Ann Levin, Scripps Institution of Oceanography, USA

\section{*Correspondence:}

Anna Metaxas, Department of Oceanography, Dalhousie University, LSC Ocean Wing, 1355 Oxford St., Halifax, NS B3H 4R2, Canada e-mail:metaxas@dal.can
Population connectivity refers to the exchange of individuals among populations: it affects gene flow, regulates population size and function, and mitigates recovery from natural or anthropogenic disturbances. Many populations in the deep sea are spatially fragmented, and will become more so with increasing resource exploitation. Understanding population connectivity is critical for spatial management. For most benthic species, connectivity is achieved by the planktonic larval stage, and larval dispersal is, in turn, regulated by complex interactions between biological and oceanographic processes. Coupled biophysical models, incorporating ocean circulation and biological traits, such as planktonic larval duration (PLD), have been used to estimate population connectivity and generate spatial management plans in coastal and shallow waters. In the deep sea, knowledge gaps in both the physical and biological components are delaying the effective use of this approach. Here, we review the current efforts in conservation in the deep sea and evaluate (1) the relevance of using larval dispersal in the design of marine protected areas and (2) the application of biophysical models in the study of population connectivity. Within biophysical models, PLD can be used to estimate dispersal distance. We propose that a PLD that guarantees a minimum dispersal distance for a wide range of species should be used in the planning of marine protected areas in the deep sea. Based on a review of data on species found at depths $>200 \mathrm{~m}$, a PLD of 35 and 69 days ensures a minimum distance for 50 and $75 \%$, respectively, of eurybathic and deep-sea species. We note that more data are required to enhance accuracy and address the high variability in PLD between and within taxonomic groups, limiting generalizations that are often appealing to decision-makers. Given the imminent expansion of resource exploitation in the deep sea, data relevant to spatial management are needed urgently.

Keywords: deep sea, connectivity, larval dispersal, biophysical models, marine reserve

\section{INTRODUCTION}

The deep sea, although the largest biome on the planet, remained unexplored until the late 19th century (Tyler, 2003) when the cosmopolitan occurrence of deep-sea fauna was established for the first time. Another 100 years of research and technological developments were necessary before the habitat heterogeneity (Ramirez-Llodra et al., 2010), high biodiversity (e.g., Grassle and Maciolek, 1992), and contribution to global ocean processes (Jahnke, 1996) of the deep sea challenged prevailing views and raised new ecological questions (Danovaro et al., 2014). In the last few decades, demand for deepsea products, such as those from fishing, hydrocarbon extraction, and mining, has been rapidly expanding (Ramirez-Llodra et al., 2011; Thurber et al., 2014), and deep-sea ecologists are asked to provide solutions for the mitigation of exploitation impacts.

Although the deep seafloor includes some of the largest contiguous features of the planet, such as the abyssal plains and the sedimentary slopes of the continental margins (Ramirez-Llodra et al., 2010), many deep-sea populations are spatially fragmented, and may become more so as a consequence of human disturbance during resource exploitation and extraction. Concurrently, one of the main challenges of deep-sea ecology is the elucidation of the processes that lead to connectivity among spatially isolated populations, which would ultimately regulate their persistence and recovery after disturbance (reviewed in Cowen et al., 2007). Differences in population connectivity contribute greatly to the spatiotemporal patterns in the distribution of organisms and 
must be considered when defining spatial management strategies, including in the design of marine protected areas (MPAs) (Gaines et al., 2003).

Many marine benthic species have complex life cycles that include a pelagic larval stage and sessile/sedentary adults (Thorson, 1964). For these species, the main process that connects populations is larval transport; consequently, the factors that regulate larval dispersal and population connectivity have been receiving increased attention. Although Thorson (1950) predicted that deep-sea animals should brood their young or have direct development, recent analyses show that pelagic lecithotrophy, rather than brooding, is the main reproductive mode in the deep sea (reviewed in Young, 2003). Different approaches have been used to evaluate population connectivity by larval dispersal including: (i) measuring the hydrodynamic and biological processes involved in larval transport (e.g., Jackson et al., 2010; Thurnherr et al., 2011; Mullineaux et al., 2013); and (ii) deriving larval origins and dispersal pathways using genetic or geochemical markers (Levin, 2006; Cowen and Sponaugle, 2009), or a combination of the two (Foster et al., 2012). To achieve a mechanistic understanding of larval transport, the interaction of biological and physical processes on different spatial and temporal scales needs to be elucidated (Cowen et al., 2007). Because sampling over all relevant scales is presently not possible, numerical models that incorporate both physical dynamics and biological traits are increasingly being used to quantify larval transport and assess its role in regulating population connectivity (e.g., Cowen et al., 2006; Siegel et al., 2008; Nolasco et al., 2013). In coastal and shallow areas, such coupled biophysical models have provided information of relevance to decision-makers in determining the spatial arrangement of marine reserves (e.g., Guizien et al., 2012; Treml et al., 2012). However, in the deep sea, this field of research is still in its infancy and fewer than a handful of studies have explored this approach (Lavelle et al., 2010; McGillicuddy et al., 2010; Yearsley and Sigwart, 2011; Young et al., 2012).

Biological parameterization of the biophysical models presents a challenge even in well studied shallow-water systems (Metaxas and Saunders, 2009). Components, such as diel and ontogenetic vertical migration, buoyancy of embryos, mortality, food availability, developmental rate, and physiological tolerances, can play an important role in dispersal patterns, and should be incorporated in biophysical models. However, most of these factors have not been studied for many species, particularly in the deep sea. In contrast, the pelagic or planktonic larval duration (PLD), commonly defined as the developmental period of a species in the water column, has been estimated for a relatively large number of marine fishes and invertebrates (Shanks et al., 2003; Shanks, 2009) and is perhaps the most often cited biological variable potentially affecting population connectivity (Sponaugle et al., 2002). Although the validity of the long-standing hypothesis that species with long larval duration also have greater dispersal potential remains equivocal (Eckert, 2003; Siegel et al., 2003; Weersing and Toonen, 2009), PLD can be used to set an upper bound on dispersal distance (Selkoe and Toonen, 2011).

In this study, we firstly provide an overview of the current efforts in conservation associated with resource extraction in deep-sea seafloor habitats and evaluate the relevance of larval dispersal in the design of marine reserves. Secondly, we review the application of biophysical models to the study of population connectivity in the deep sea, and provide an evaluation of their performance. Lastly, we assess the extent of the current knowledge on PLD for deep-sea species as one of the main biological components consistently included in biophysical models. We then compare the available estimates from the deep sea with those from the closest taxonomic relatives that live in shallow systems to determine whether PLD is taxonomically conserved. Genetic tools have also been used in many studies to estimate dispersal distances and genetic connectivity, which we do not review here. A separate synthesis is underway, focused specifically on geneticbased estimates of deep-sea dispersal distances, including analyses of how different life-history factors may affect these estimates and that compare these estimates with those in shallow water (A. Baco et al in prep). These two syntheses are parallel products of the Population Connectivity working group of INDEEP (International Network of Scientific Investigations of Deep-Sea Ecosystems; www.indeep-project.org/). The ultimate goal is to provide recommendations for obtaining accurate estimates of larval dispersal and population connectivity that can be used on the spatial management of different deep-sea habitats.

\section{USING LARVAL DISPERSAL IN THE DESIGN OF MARINE RESERVES IN THE DEEP SEA}

With the depletion of mineral and biological resources on land and in coastal waters, resource extraction has been extending into the water column and the seafloor of the deep sea. Oil and gas have long been extracted offshore, in waters $>200 \mathrm{~m}$ in depth. The Deepwater Horizon blowout in the Gulf of Mexico in 2010 was the largest oil spill in history (in terms of amount of oil spilled) and one that occurred directly on the seafloor of the deep sea. It impacted deep-water coral communities as far as $22 \mathrm{~km}$ away from the accident site at depths of 1850-1950 m (Fisher et al., 2014). The presence of some of these communities was unknown until surveys were conducted after the oil spill. The continuous expansion of oil and gas exploration onto the continental margins all around the globe is greatly enhancing the threat for similar accidents and impacts. Deep-water fishing has been occurring since the late 1950s but developed into a commercial industry in the last 40 years. The impact of bottom trawling on both deep-sea fish and benthic communities has been highlighted by a number of studies (Koslow et al., 2000; Bailey et al., 2009), and growing concern has resulted in recent proposals for a ban on deep-sea bottom trawling in European waters. An emerging potential pressure on the seafloor is through the development of deep-ocean industrial mining, which is rapidly gaining momentum. Deep-sea mining will potentially encompass polymetallic nodules in the abyssal plains, deposits of seafloor massive polymetallic sulfides (SMS) from hydrothermal vents, cobalt crusts from seamounts, among others. As of mid-2014, the International Seabed Authority (ISA) had granted 16 exploration contracts in the Atlantic, Pacific and Indian Oceans, covering all three types of resources (ISBA, 2014). However, deep-sea mining will occur both in national and international jurisdictions, and the laws and regulations that will apply to the industry are currently still under development. 
Although the extraction methods can potentially be highly destructive, the spatial and temporal scales of their impact are not known. Additionally, both the biological communities and the drivers that regulate these communities are mostly unknown, particularly in the abyssal plains, but even at some of the hydrothermal vents and seamounts currently being targeted for exploration. A high probability of endemicity at some of these locations further underscores the potential impact of unfettered anthropogenic activities on these largely undescribed ecosystems. For these reasons, a recent call for the precautionary approach in the management of human activities in the deep sea includes plans for protection of the ecosystems, research to increase knowledge, and governance collaboration across sectors (Mengerink et al., 2014).

The strategies being considered for spatial management and protection in the deep sea are based on our existing practices from shallow waters: MPAs or other marine reserves partially or fully restricting certain human activities (Halpern, 2003). The spatial arrangements of marine reserves can vary from a single reserve to a network of many reserves within a habitat or region, but the target is usually a subset of habitats (or species) in a region (Hastings and Botsford, 2003; Sale et al., 2005). The selection of the subset of habitats to be protected is based on how representative they are within the region of interest, their uniqueness or rarity, their vulnerability to potential threats or presumed slow recovery from disturbance, whether they support high biodiversity or high productivity, or whether they are a key habitat for a particular stage in the life-history of species, particularly if the latter is threatened or endangered (CBD, 2007). Many of these selection criteria apply to habitats in the deep sea, particularly their vulnerability and presumed slow recovery from perturbation and high biodiversity (e.g., the abyssal plains), uniqueness (e.g., hydrothermal vents) and importance to certain life-history stages (e.g., seamounts). For a network of marine reserves or MPAs, additional criteria apply, such as maximizing connectivity between individual MPAs and maintaining viable populations across the network. These last two criteria are closely linked, particularly in spatially fragmented populations where persistence of a population will depend on either sufficiently large local replenishment in a single patch or, in its absence, sufficiently strong connectivity among patches in a network (Burgess et al., 2014). Since larval dispersal influences population connectivity (Cowen and Sponaugle, 2009), knowledge of the magnitude and pathways of dispersal can be critical elements in the design of effective marine reserves.

The concept of marine reserves in the deep sea in the face of potentially heightened exploitation is increasingly gaining support. An example from areas under international jurisdiction include an environmental management plan for the ClarionClipperton Zone (CCZ), generated by the International Seabed Authority (ISA) in which the Authority acknowledges its responsibility to afford effective protection of the environment from harmful effects of prospecting, exploitation and exploration activities (ISBA, 2011). The conservation objectives were to maintain regional biodiversity, ecosystem structure and ecosystem function across the CCZ, manage the CCZ consistently with the principles of integrated ecosystem-based management, and enable the preservation of representative and unique marine ecosystems. Based on environmental and ecological data, which included (presumed) faunal dispersal capabilities and distances, the ISA recommended the allocation of 9 areas of environmental interest, within each of 9 biogeographic subregions, each $400 \times$ $400 \mathrm{~km}(\mathrm{a} 200 \times 200 \mathrm{~km}$ core area surrounded by a $100-\mathrm{km}$ buffer zone) (ISBA, 2011; Wedding et al., 2013). The size of each area was presumed to be sufficient for each to maintain viable populations of species potentially restricted to a sub-region. Assessing the viability of a population requires the combined estimates of larval retention, reproductive output of the population, and population size at minimum (Burgess et al., 2014); this information largely did not exist when ISA made its recommendations. Further examples of marine reserves in the deep sea include the OSPAR network of MPAs in the North East Atlantic (OSPAR, 2003) as well as bottom trawl closures on the Mid Atlantic Ridge and various seamounts for the protection of vulnerable marine ecosystems (NEAFC, 2011). Within national jurisdiction, a few MPAs (or a national monument in the case of the US) have been established for the protection, at least in part, of deepsea hydrothermal vents and they include the Endeavor Segment (Canada), the Marianas Trench region (USA), the mid-Atlantic Ridge off the Azores (Portugal), and the Guaymas Basin and Eastern Pacific Rise (Mexico). In addition, particularly within Europe and the USA, a number of MPAs have been established for the protection of vulnerable deep-sea habitats, principally cold water corals and deep-sea sponges. Generally, the conservation objectives and management plans of these align with those agreed upon in the Convention of Biological Diversity. As in the example with the CCZ, for all of the national MPAs, the information required to assess population connectivity and viability was weak to non-existent.

Recommendations on the spatial management through marine reserves have also been made by the scientific community directly. For example, the Dinard workshop, attended by stakeholders from various sectors and 14 countries provided a clear set of guidelines for setting up reserves in chemosynthetic environments (Ardron et al., 2011; Van Dover et al., 2012). The proposed design followed the same criteria as recommended for shallow water MPAs, including "ensuring connectivity" among reserves (Van Dover et al., 2012). Clark et al. (2014) assessed how each of the criteria for the selection of Ecologically and Biologically Significant Areas (EBSAs), described above in the context of MPAs, can be applied to deep-sea ecosystems, and provided a test case on seamounts in the Pacific Ocean. Other studies have addressed the management requirements and have made recommendations for conservation specifically with respect to mining SMS deposits, cobalt-rich crust regions on seamounts and manganese nodules in abyssal plains (Boschen et al., 2013; Wedding et al., 2013; Schlacher et al., 2014). Boschen et al. (2013) recommended the establishment of "preservation reference zones" during SMS mining, including upstream set-asides that can supply colonizing larvae, in addition to preserving an unimpacted section of the population. Wedding et al. (2013) provided a systematic framework for conservation in abyssal plains, including the incorporation of design principles utilized in shallow water, such as ecosystem-based management and networks of MPAs. The concepts of realized dispersal distances and the size of each MPA in the network, particularly as they relate to 
population viability, were addressed in the framework (Wedding et al., 2013).

While spatial planning is gaining attention in the context of deep-sea resource extraction, the data to support decisions are scarce. Classification systems of deep-sea habitat are being developed on which the criteria of representation of habitats within MPA networks may then be assessed (Howell, 2010; Howell et al., 2010), and species-area relationships have been used to inform baseline conservation targets for the deep North East Atlantic (Foster et al., 2013). Although recent science-based studies have started to address their relevance to the conservation of potentially vulnerable ecosystems in the deep sea (e.g., Rengstorf et al., 2013; Ross and Howell, 2013; Jackson et al., 2014; Nakajima et al., 2014), studies designed specifically to collect relevant data are still lacking. In addition to the attention being recent, the logistical constraints in collecting data from a remote environment, such as the deep sea, are great. Data on larval dispersal and population connectivity that are purported to be relevant in the design of marine reserves are particularly difficult to obtain, even in the more accessible shallow-water ecosystems (Burgess et al., 2014). Numerical models are one promising approach allowing the calculation of dispersal matrices under different scenarios, and their performance can be progressively improved with gaining biological and physical information.

\section{APPLICATIONS OF BIOPHYSICAL MODELS TO LARVAL DISPERSAL}

Lagrangian particle tracking methods, traditionally employed by atmospheric scientists and oceanographers, can be used to simulate the release of passive particles to track the fate of the advected drifters in the ocean. These passive drifters can be used to represent theoretical larvae in order to identify likely dispersal pathways, highlighting the oceanographic mechanisms and barriers to dispersal (Werner et al., 2007). Particles can also be given "behavior," simulating swimming abilities such as diel vertical migration or ontogenetic buoyancy properties, to adjust predictions where dispersal is likely not passive (Levin, 2006; Werner et al., 2007).

Many of the biological parameters (e.g., planktonic larval duration, larval buoyancy, mortality over time, vertical migration, settlement probability, settlement behavior) included in the biophysical models cannot be estimated at this time for marine benthic species (in shallow or deep waters) (Metaxas and Saunders, 2009). Where these data are available, they may alter estimates of connectivity (Cowen et al., 2000). Many tracer parameters require data derived from biological traits, such as number of particles released (fecundity), particle release depth (spawning location), and particle tracking time (planktonic larval duration). The accuracy in these tracer characteristics along with rate of particle loss from the system (mortality) and "behavior" is the challenge that biologists face when they attempt to predict and validate dispersal pathways (Metaxas and Saunders, 2009).

Biophysical models can be applied over a variety of time scales (Levin, 2006) and studies based on contemporary time scales can provide insight into current metapopulation management and demographic dynamics (Cowen and Sponaugle, 2009). Modeling can be used to define the average route and distance of dispersal paths from a release site (Cowen et al., 2007; Cowen and Sponaugle, 2009; Kool et al., 2013) and provide retention estimates and, thus, inform MPA networks (Paris and Cowen, 2004; Treml and Halpin, 2012). Most modeling studies are used to explore the effect of physical drivers on dispersal (Martins et al., 2010; Blanke et al., 2012; Soria et al., 2012; Young et al., 2012) but, in a system where knowledge of life-history traits is lacking, null models can test the effects of behavior on dispersal (Paris et al., 2007, 2009; Carr et al., 2008; Sundelöf and Jonsson, 2012), the relationship between PLD and dispersal ability (Siegel et al., 2003; Young et al., 2012), and the role of other abiotic/biotic factors in dispersal (Ayata et al., 2010; Martins et al., 2010; McGillicuddy et al., 2010; Treml and Halpin, 2012). The ability to run a model both forwards and backwards in time also allows for the prediction of both sources and sinks of propagules (Brickman et al., 2009). Results from these modeling efforts can then be compared to empirical data for biological validation (e.g., Foster et al., 2012), while also being used to constrain dispersal estimates within an ecological timeframe.

Because of the paucity of data on life histories of deep-sea fauna as well as deep-sea circulation, accurate modeling and precise validation are not feasible at this point. Basic models, which exclude life-history data can provide estimates of the bounds of dispersal ranges for future validation and hypothesis generation. Studies on population connectivity in the deep sea may benefit from biophysical modeling more than in shallow environments, given the inherent barriers of accessibility, scale and expense associated with the collection of samples. However, sampling is still required for validation of models and predictions.

\section{CHOOSING PHYSICAL MODELS FOR DISPERSAL STUDIES IN THE DEEP SEA}

Horizontal dispersal of planktonic propagules, such as larvae, is primarily passive, i.e., the greatest component of displacement is through advection by the oceanic velocity field. If the velocities are known across all scales of interest, dispersal reduces to a problem of advection. If, as is usually the case, knowledge of the velocity field is incomplete, the effects of the unknown velocities must be parameterized somehow. Often, the unresolved velocities are modeled as random-walk processes (e.g., Berg, 1993), which cause down-gradient fluxes proportional to the spatial gradients (Fickian diffusion), leading to advection-diffusion models.

There is a hierarchy of techniques that has been used to infer bounds on planktonic dispersal in the deep sea using advectiondiffusion models, with the simplest ones being either purely advective or diffusive. The simplest advective model uses a representative "mean" velocity together with PLDs to estimate a dispersal distance (e.g., McClain and Hardy, 2010). As this model ignores both spatial and temporal variability in the velocity field, the relevance of the resulting estimates is restricted to temporal and spatial scales over which the circulation can be considered steady and homogeneous. On time scales that typically range from weeks to months and even years, horizontal dispersal across most of the deep ocean is either dominated or strongly affected by eddy diffusion (Speer et al., 2003), implying that advection-bymean-flow models are not appropriate. Another simple technique that has sometimes been used to estimate dispersal distances 
is based on progressive vector diagram (PVDs) derived from Eulerian measurements (e.g., Marsh et al., 2001). While temporal variability of the velocity field is included in this method, spatial variability is not, restricting the relevance of the resulting estimates to the scales of the processes that dominate the velocities, such as eddies, Rossby waves, equatorial jets, and boundary currents. In particular near sloping topography (continental slopes, seamounts, mid-ocean ridges, etc.), the spatial scales of subinertial oceanic flows are often on the order of kilometers (e.g., Brink, 1995; Cannon and Pashinski, 1997; Stahr and Sanford, 1999; Thurnherr and Richards, 2001; McGillicuddy et al., 2010; Thurnherr et al., 2011), limiting the use of PVDs to temporal and spatial scales of days and $10 \mathrm{~s}$ of kilometers at most.

Given the difficulty of observing the velocity field in the deep ocean across a wide range of spatial and temporal scales, numerical ocean general circulation models (OGCMs) are often the only viable option for obtaining the velocities that are required to study larval dispersal. However, it is unlikely that all physical processes will be captured in a single OGCM: their greatest inadequacies are in relation to the processes occurring at the fine spatial and temporal scales which are of greatest relevance to a larva (Metaxas and Saunders, 2009). For example, Lacroix et al. (2009) suggested that a $3-\mathrm{km}$ grid is required to resolve a 20 $\mathrm{km}$ eddy indicating the intensity of data coverage required to resolve sub-mesoscale and small scale processes. Because of the small scales involved, modeling the circulations near topography often requires dedicated regional models with high spatial and temporal resolution (e.g., Proehl et al., 2005; Mitarai et al., 2009; Lavelle et al., 2010; McGillicuddy et al., 2010), which can be hard to source. As even the highest-resolution regional models cannot resolve the small scales associated with mechanical turbulence, the effects of sub-gridscale processes on dispersal should be parameterized, in particular when vertical dispersal is to be investigated (e.g., Proehl et al., 2005).

Modeling of vertical dispersal requires sufficient vertical resolution in the velocity fields. The vertical resolution of most "general-purpose" models is typically quite coarse below the thermocline, where the vertical gradients of temperature and salinity, and the corresponding diffusive fluxes, tend to be small. Such models are less suitable for simulating vertical dispersal of tracers and propagules that are associated with strong vertical gradients, such as larvae released at the seabed, which set the diffusive vertical fluxes between adjacent grid cells or isopycnal layers. Within a grid cell or layer, diffusive vertical dispersal in a numerical model is instantaneous due to the standard assumption that any particles contained within a cell are distributed uniformly across its volume. In reality, it may take $\sim$ a year for a tracer sheet to diffuse across a vertical distance of $100 \mathrm{~m}$ in the deep ocean, away from the immediate vicinity of topography (Ledwell and Watson, 1991; Ledwell et al., 1993, 2011). As a result, simulated vertical dispersal of propagules can be much more rapid than in the real ocean, even in models with accurate diffusive fluxes of heat, salt, oxygen, nutrients, etc. It is noted that fine vertical resolution is typically also required to simulate the small scales associated with the topographic flows discussed above. Such inaccuracies in this advective/diffusive vertical dispersion parameter will be exacerbated if any biological parameters are also used to modify vertical position within a model (e.g., buoyancy or vertical swimming behavior), so care must be used to minimize or acknowledge the error here.

Another important consequence of unresolved sub-gridscale processes in numerical models is that validation with velocity measurements is difficult, as the model velocities represent spatial averages over grid cells. As a result, direct comparisons between observed and modeled velocity time series often show sizable differences, even for high-resolution regional circulation models that have considerable skill in predicting dispersal as validated, for example, with tracer-release experiments (e.g., Proehl et al., 2005; Lavelle et al., 2010; McGillicuddy et al., 2010). In general, Lagrangian data from tracer and dye release experiments, and from float and drifter trajectories are more suitable for validating the dispersal characteristics of a model than Eulerian velocity measurements, because they integrate the effects of all processes affecting dispersal, regardless of their scales. While Lagrangian experiments are expensive and difficult to carry out, especially in the deep ocean, there are data available from previous and ongoing deep tracer-release experiments (e.g., Ledwell and Watson, 1991; Ledwell et al., 1993, 2000, 2011; Jackson et al., 2010) and float studies (e.g., Hautala and Riser, 1993; Hogg and Owens, 1999; Argo data http://www.argo.ucsd.edu/) that can be used to validate the dispersal characteristics of large-scale circulation models, at least in some regions of the deep ocean.

The choice of an appropriate OGCM, including subgridscale parameterizations, is key in the process of model parameterization. It should be recognized that OGCMs are generally not designed explicitly to estimate larval dispersal. Consequently, a model designed (and validated) to represent global thermohaline circulation may perform less well within particular regions (Fossette et al., 2012). Further complications arise in the choice of particle tracer. Online particle tracers run natively within the OGCM utilizing the full resolution model output to infer advection and diffusion, but access and computational restrictions can become prohibitive for repeated runs (North et al., 2009; Fossette et al., 2012). Offline particle tracer models (Supplementary Table 1) use outputs from OGCMs, with both the offline models and OGCM outputs being more accessible. However, outputs from temporally and spatially highly resolved OGCMs are often averaged to lower resolutions to reduce the required storage capacity. This averaging can in turn reduce the resolution of captured hydrographic phenomena, e.g., de-trending tides and smoothing eddies, potentially resulting in erroneous trajectory predictions (Putman and He, 2013). Sensitivity analyses can be very informative in terms of the limitations and predictive ability of an OGCM/particle tracer coupling, and can assist in model choices and discourage "black box" model usage (Simons et al., 2013). Coupled with study specific validation, sensitivity analysis is an advisable step prior to settling upon model choice and asking questions of dispersal (North et al., 2009).

\section{PARAMETERIZING THE BIOLOGY FOR BIOPHYSICAL MODELS IN THE DEEP SEA: THE ROLE OF PLANKTONIC LARVAL DURATION}

Most marine benthic species exhibit a biphasic life cycle, which includes a pelagic larva, but there are exceptions such as pericarid 
crustaceans and nematodes that have direct development. Hence, models of the distribution of benthic organisms typically incorporate species-specific biological parameters that account for this potentially dispersive larval phase. The most frequently utilized is the PLD during which larvae are susceptible to physical mixing and advection (Sponaugle et al., 2002; Treml et al., 2008). In spite of its reference to larval development, values of PLD provided in the literature often encompass the entire development between egg release and settlement, although such data would be best described as planktonic propagule duration (PPD; embryonic + larval phase). Because embryos (to late gastrula) may differ from larvae in physical properties (e.g., shape, buoyancy) and swimming capacity, a true PLD (restricted to the larval phase) may be distinguished from PPD, where such data are available (e.g., Brooke and Young, 2009; Selkoe and Toonen, 2011; Mercier et al., 2013). A clearer distinction enables the inclusion of passive vs. active dispersive phases (e.g., egg/embryos vs. larvae), as well as transient planktonic phases in species that undergo parental care or demersal development for a portion of the embryonic or larval phases (e.g., certain gastropods, polychaetes and anthozoans).

Taken as the length of the planktonic phase, PLD has long been a central variable of biophysical models (Sponaugle et al., 2002; Lett et al., 2010; Liggins et al., 2013). The simplest models assume that pelagic propagules are passive and that population connectivity is therefore inversely related to PLD (e.g., in reef fishes; Roberts, 1997). However, the strength of the relationship between PLD and dispersal is being debated (Paulay and Meyer, 2006; Strathmann, 2007; Shanks, 2009; Weersing and Toonen, 2009; Selkoe and Toonen, 2011; Mercier et al., 2013). The emerging view is that dispersal is not only determined by the length of the planktonic phase, but also by circulation processes (e.g., Watson et al., 2010) and larval behavior (e.g., Metaxas and Saunders, 2009; Shanks, 2009; Butler et al., 2011). Hence, the use of PLD in combination with other biological variables is now gaining favor in designing biophysical models of species recruitment and population connectivity (Sponaugle et al., 2002; Levin, 2006; Fiksen et al., 2007; Gilbert et al., 2010; Domingues et al., 2012; Treml et al., 2012; Kough et al., 2013; Nicolle et al., 2013; Nolasco et al., 2013). Fine predictions tend to include many biotic variables. For instance, the LARVAHS model proved to be effective at estimating recruitment success in clams, emphasizing the role of PLD, as well as habitat suitability, larval swimming behavior, wind patterns (seasons), spawning ground location and tidal phase at spawning (Bidegain et al., 2013). Nevertheless, simpler models can be relatively robust. A recent study of invertebrate and fish larvae showed that PLD and depth distribution explained 80\% of total variation in dispersal distance, whereas spawning season, and geographic and annual variations in circulation had only marginal effects (Corell et al., 2012). Conversely, differences in reproductive seasons were determined to drive opposite sourcesink dynamics in two congeneric mussel species (Carson et al., 2010). Testing various idealized larval behaviors also supported the role of vertical swimming/migration during planktonic development as a key determinant of nearshore settlement site (Drake et al., 2013).

While it may be desirable, the inclusion of several biotic variables, particularly behavioral traits, is generally more difficult for deep-sea than for shallow-water species. Even obtaining reliable estimates of PLDs can present a challenge; however, the coupling of PLD with oceanographic data can provide estimates of the upper bounds of dispersal distances (Young et al., 2012). To date, PLDs have been estimated for deep-sea species using four different methods: (1) larval culture in the laboratory, which presents several challenges in terms of maintaining appropriate rearing conditions, or in the field which may not allow for the completion of the life cycle; (2) computation of PLD from metabolic rates and available energy stores, which is valid only for lecithotrophic larvae; this approach also requires knowledge of the relationship between temperature and metabolic efficiency that for most deepsea species can only be assumed; (3) tracking of larval cohorts in the plankton, an approach only possible for species with discrete spawning periods; and (4) calculation based on the timings of settlement and spawning times, which also may require backcalculation of settlement time using juvenile growth rates, seldom known for deep-sea species.

\section{ANALYSIS OF EXISTING DATA ON PLANKTONIC LARVAL DURATIONS IN THE DEEP SEA}

We assessed the current knowledge on planktonic larval durations (PLD) for deep-sea species and compared the available estimates with those from shallow-water species, using published observational and experimental PLD values for 305 species belonging to seven marine benthic phyla (Table 1, Supplementary Data): Cnidaria (12), Annelida (25), Sipuncula (1), Mollusca (31), Arthropoda (68), Echinodermata (167), Chordata (1). When multiple PLD values were available in the literature for the same species, only the minimum and maximum values were kept for analyses and used to calculate the median PLD; when only one value was available in the literature that value was used as minimum, maximum and median in all analyses.

Species were classified according to their bathymetric distribution into shallow (0-200 m), eurybathic $(0->200 \mathrm{~m})$ and deep ( $>200 \mathrm{~m}$ ). In total, PLD estimates were available for 212 shallow, 72 eurybathic and 21 deep-sea species (Table 1). Eurybathicliving below $200 \mathrm{~m}$ and deep-sea species were further categorized according to their habitat (Figure 1). The relatively high number of species from the sedimentary slope (excluding other specific sub-habitats found on slopes such as cold-water corals, cold seeps;

Table 1 | Number of species for which PLD has been estimated.

\begin{tabular}{|c|c|c|c|c|c|c|c|c|}
\hline & Total & Cnidaria & Annelida, Polychaeta & Sipuncula & Mollusca & Arthropoda, Crustacea & Echinodermata & Chordata,Tunicata \\
\hline Shallow & 212 & 6 & 20 & 0 & 27 & 48 & 111 & 0 \\
\hline Eurybathic & 72 & 3 & 1 & 0 & 2 & 14 & 52 & 0 \\
\hline Deep & 21 & 3 & 4 & 1 & 2 & 6 & 4 & 1 \\
\hline
\end{tabular}


$N=75$ ), for which the PLD has been investigated is the result of numerous reproductive studies on echinoderms with a eurybathic distribution $(N=52)$; echinoderms are the best-studied group of deep-sea animals in terms of reproduction (Young, 2003) and are the taxonomic group for which many PLD values are available. Apart from these, PLD from species living below $200 \mathrm{~m}$ depth has been investigated mostly for polychaetes, molluscs, and crustaceans from chemosynthesis-based habitats (hydrothermal vents and cold seeps, $N=12$ ) since questions related to how these insular and ephemeral habitats are maintained and new sites colonized by larvae have been of much interest in recent decades (Tyler and Young, 1999; Metaxas and Kelly, 2010). We examined differences in PLD among shallow, eurybathic and deep species (available values pooled within each of these three categories) with a Kruskal-Wallis test, followed by Dunn's multiple comparisons using the statistical software GraphPad Prism (version 6.0).

The ranges in minimum, maximum and median PLD were quite wide for all three bathymetric distributions (Table 2).

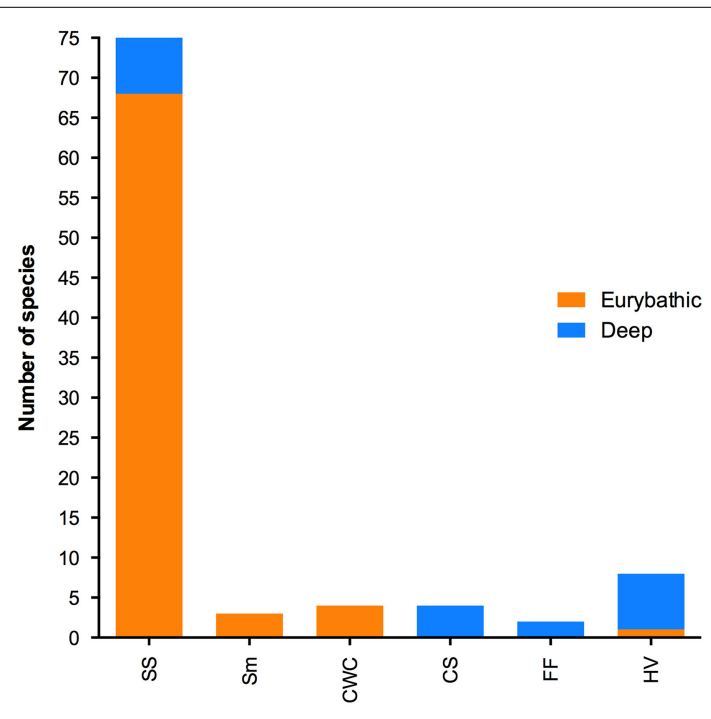

FIGURE 1 | Number of deep-sea and eurybathic species for which PLD has been estimated in different deep-sea habitats (SS, sedimentary slope; Sm, seamounts; CWC, cold water coral; CS, cold seeps; FF, food falls; HV, hydrothermal vents).
Statistically significant differences were found between shallow and both eurybathic and deep species; PLD values of eurybathic and deep-sea species were not significantly different from one another (Table 3). Overall, shallow-water species present shorter PLD than eurybathic and deep species (Figure 2, Table 2).

PLD estimates have been included in biophysical models to set boundaries on dispersal distances of individual species. However, in the context of spatial planning, connectivity is often not considered for single species, but rather between different areas. Models can estimate the durations that would be required to connect particular metapopulations; however, in most cases there is insufficient data on the distribution of deep-sea species to use this methodology. An alternative approach would be to incorporate in the models a PLD value that guarantees a minimum dispersal distance for a wide range of species. Based on the existing data, we propose that a PLD of 35 and 69 days ensures a minimum distance for 50 and $75 \%$, respectively, of the eurybathic and deep-sea species in our study (Figure 3). Despite its potential utility, the paucity of data points and the high variability in PLD between and within taxonomic groups underscore the limitations of our proposal.

The current knowledge on the PLD of deep-sea species is scarce and unevenly distributed between habitats and taxonomic groups (Figure 4), limiting generalizations that are often appealing to decision-makers. More data on the larval ecology is undoubtedly necessary to develop effective conservation strategies for deep-sea habitats and species. Nevertheless, the few biophysical models integrating estimates of larval duration have already generated important information to understand dispersal and connectivity in the deep sea (e.g., Marsh et al., 2001; Yearsley and Sigwart, 2011; Young et al., 2012).

\section{USING BIOPHYSICAL MODELS TO PREDICT DISPERSAL IN THE DEEP SEA}

Only a handful of studies have attempted to model larval dispersal in the deep sea, and most of these have been limited by the availability of reliable estimates of biological parameters, including planktonic larval duration, spawning season, and dispersal depth. Consequently, most modeling exercises to date have been experiments that attempt to identify the biological values required to produce a given distributional or genetic pattern. In one of the earliest such studies, Chevaldonné et al. (1997) used a particle flux model to estimate the magnitude of dispersal required by larvae of

Table 2 | Descriptive statistics of the available minimum, maximum and median PLD values (days) for shallow $(N=212)$; eurybathic ( $N=72$ ) and deep species ( $N=20$; the value of 660 days determined for Sclerasterias tanneri was not included).

\begin{tabular}{|c|c|c|c|c|c|c|c|c|c|}
\hline & \multicolumn{3}{|c|}{ Shallow } & \multicolumn{3}{|c|}{ Eurybathic } & \multicolumn{3}{|c|}{ Deep } \\
\hline & Min. & Max. & Median & Min. & Max. & Median & Min. & Max. & Median \\
\hline Range & $0.17-293$ & $0.17-293$ & $0.17-293$ & $1-167$ & 5-167 & $3-167$ & $1-240$ & $10-420$ & $10-315$ \\
\hline Mean & 25 & 30.35 & 27.68 & 43.13 & 53.26 & 48.14 & 73.40 & 119.9 & 96.63 \\
\hline St. Dev. & 27.85 & 30.35 & 28 & 34.93 & 37.87 & 35 & 76.87 & 112.0 & 85 \\
\hline Median & 18.00 & 24.00 & 22.75 & 33.50 & 46.50 & 42.00 & 44.50 & 94.00 & 66.25 \\
\hline $\mathrm{Q}_{25}$ & 8.25 & 13.25 & 11.63 & 19.25 & 21.00 & 21.00 & 12.50 & 39.00 & 30.13 \\
\hline $\mathrm{Q}_{75}$ & 33.75 & 40.75 & 36.38 & 64.00 & 78.75 & 74.75 & 120.0 & 151.8 & 143.3 \\
\hline
\end{tabular}


Table 3 | Results of the Kruskal-Wallis and Dunn's multiple comparison tests used to investigate differences of minimum, maximum and median values between shallow, eurybathic and deep species.

\begin{tabular}{|c|c|c|c|c|c|c|c|c|}
\hline \multicolumn{3}{|c|}{ Kruskal-Wallis } & \multicolumn{6}{|c|}{ Dunn's multiple comparison } \\
\hline & $\mathbf{K}$ & $p$ & Mean rank diff. & $p$ & Mean rank diff. & $\boldsymbol{p}$ & Mean rank diff. & $p$ \\
\hline Min. PLD & 24.39 & $<0.0001^{*}$ & -53.00 & $<0.0001 *$ & -58.18 & $0.0139 *$ & -5.182 & $>0.9999$ \\
\hline Max. PLD & 43.93 & $<0.0001^{*}$ & -58.10 & $<0.0001^{*}$ & -106.7 & $<0.0001 *$ & -48.46 & 0.0865 \\
\hline
\end{tabular}

*indicates statistically significant differences. The value of 660 days determined for Sclerasterias tanneri was not included.

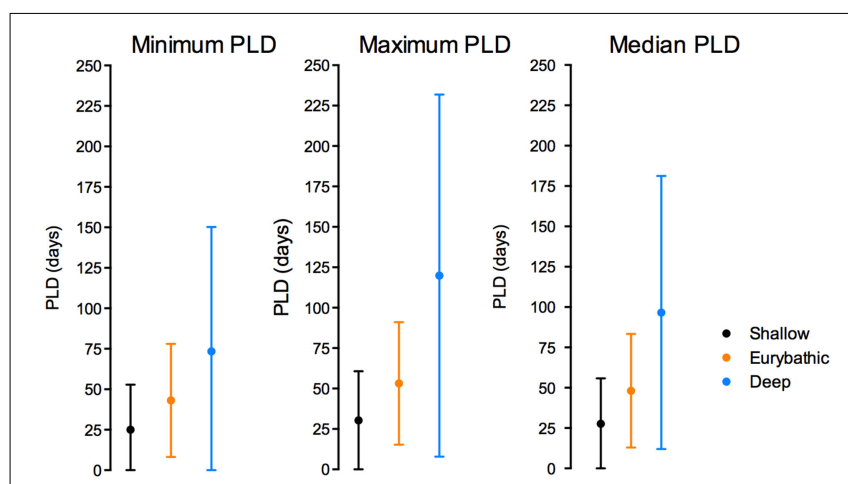

FIGURE 2 | Mean and standard deviation of minimum (left), maximum (middle) and median (right) PLD values for shallow, eurybathic and deep-sea species. The value of 660 days determined for Sclerasterias tanneri was not included.

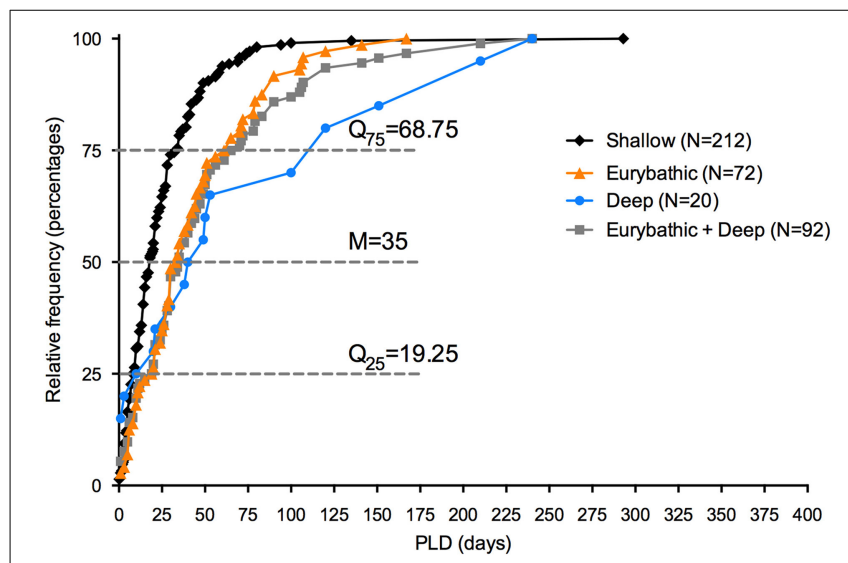

FIGURE 3 | Histogram of frequency of minimum PLD estimates available for shallow, eurybathic and deep-sea species. Median, percentile 25 and 75 are shown for PLD values of eurybathic and deep-sea species pooled together. The value of 660 days determined for Sclerasterias tanneri was not included.

the vent worm Alvinella pompejana to reach known vent sites on the East Pacific Rise (EPR). Short PLDs and lecithotrophic development were assumed based on circumstantial evidence, and the resulting simulations did not agree with an observed absence of genetic structure over large spatial scales. To explain the absence of genetic structure, the authors invoked spatially variable and frequent geological events, rather than the possibility that dispersal times were longer than assumed. Subsequent embryological studies with the same species (Pradillon et al., 2001, 2005) suggested a mechanism of developmental arrest at cold temperatures that could easily reconcile the genetic data with model predictions and confirming that lecithotrophic development does not necessarily result in short PLD (e.g., Shilling and Manahan, 1994).

Using progressive vector models based on Eulerian current measurements during a single year, Marsh et al. (2001) predicted the dispersal potential of the vent tubeworm Riftia pachyptila on the EPR. Reliable estimates of PLD were based on laboratory and in situ larval rearing, as well as metabolic measurements predicting the depletion rate of internal lipid stores. The models predicted peak dispersal distances at $\sim 103 \mathrm{~km}$, with high cumulative mortality by the terminal (presumably competent) larval stages. In a subsequent study, Brooke and Young (2009) showed that $R$. pachyptila disperse as unciliated embryos for the first 3 weeks of their 5-week development. If this observation is superimposed on the mortality schedule estimated by the simulations of Marsh et al. (2001), one must conclude that more than half of the individuals are lost from the vent system before they even become larvae. Brooke and Young (2009) also showed that ontogenetic migration by this species is limited by larval tolerance to the warm temperatures and low pressures that prevail in the shallower depths of the water column. The progressive vector approach of Marsh et al. (2001) was extended from $9^{\circ} \mathrm{N}$ to $13^{\circ} \mathrm{N}$ on the EPR by Mullineaux et al. (2002) who estimated dispersal distances for theoretical larvae with both shorter and longer PLDs than those determined empirically for Riftia pachyptila.

The dispersal of simulated larvae from hydrothermal vents as either passive particles or "balloonists" that migrate ontogenetically to and from the upper water column was modeled by McGillicuddy et al. (2010). The model was both driven and validated with data from moored current meters and particle trajectories based on larval releases every $12 \mathrm{~min}$ in all seasons of the year. The model assumed a 30-day dispersal period as predicted by Marsh et al. (2001) for Riftia pachyptila. This modeling exercise yielded several important conclusions, including the observation that larvae released at the crest of the EPR dispersed greater distances near the sea floor than higher in the water column. This result suggests that ontogenetic migration is not a viable strategy for increasing dispersal in this system and is in agreement with the physiological tolerances reported by Brooke and Young (2009). 


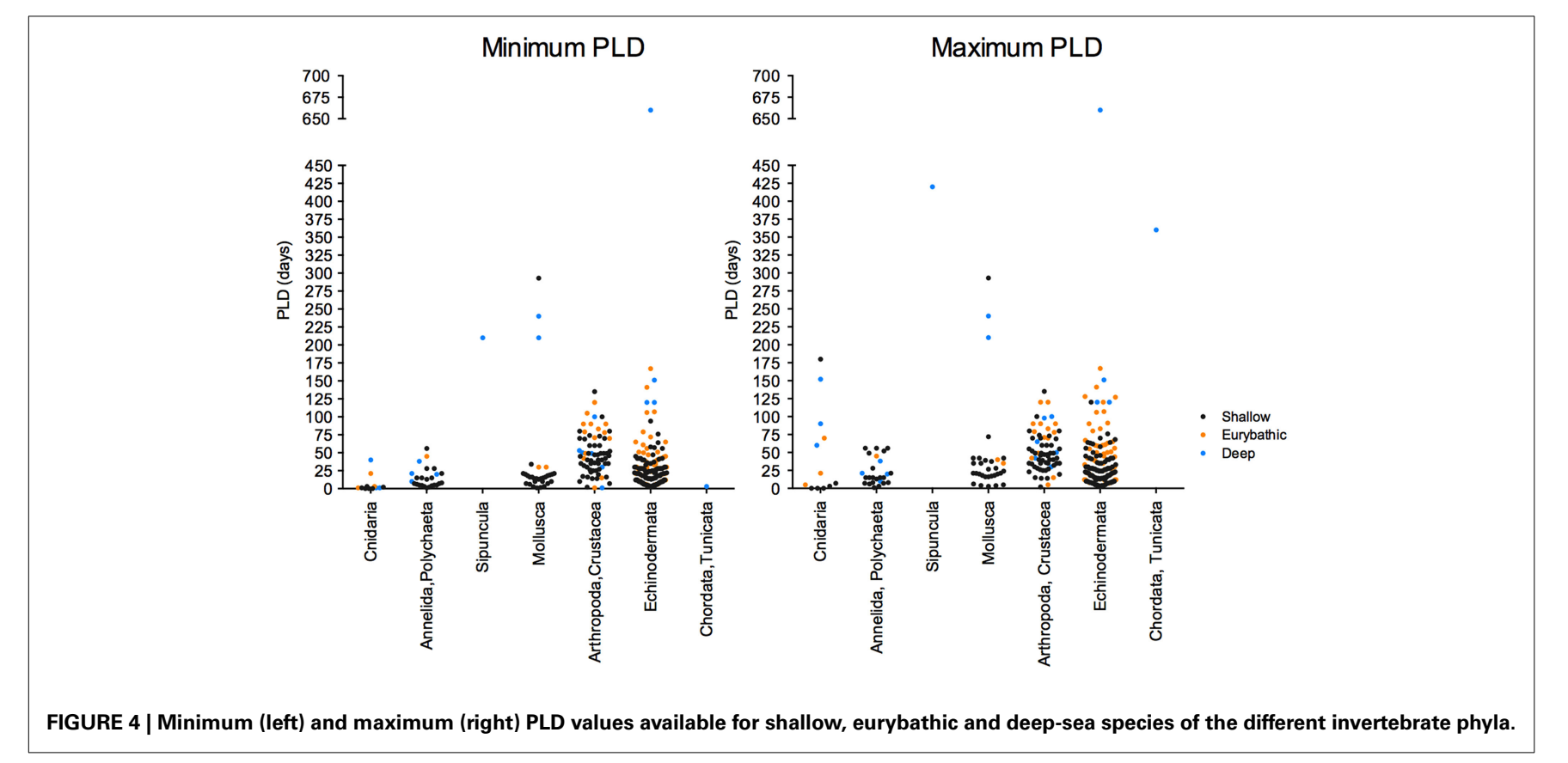

McGillicuddy et al. (2010) explained this pattern with reference to observed vigorous along-flank flows and high flow variability near the ridge axis, but were not able to test these hypotheses empirically with their moored current meter data. Another important conclusion was that the likelihood of successful settlement varied significantly with time of year. Larvae "released" in early summer were much less likely to find themselves near a suitable settlement site than ones released in winter. Lastly, the model showed that the period of precompetency may play a highly significant role in successful dispersal. As predicted by Jackson and Strathmann (1981), larvae that spend a higher percentage of their time being able to undergo metamorphosis will be more likely to encounter suitable habitat during that period. In the case of R. pachyptila, however, the developmental observations (Marsh et al., 2001; Brooke and Young, 2009) indicate that metamorphic competency is not attained until the very end of larval life.

In non-chemosynthetic habitats of the deep sea, Yearsley and Sigwart (2011) used a biophysical model to estimate connectivity among known populations of deep-sea chitons in archipelagos of the Southwest Pacific. Because there were no biological parameters available for any of the species examined, the models were based on several assumptions inferred from shallow-water species with known larval development. Because all known chitons from shallow water have lecithotrophic development, it was reasonably assumed that deep-water species would have the same developmental mode. Planktonic larval duration is unknown for any deep-sea chiton, and this important parameter was extrapolated from known shallow-water PLDs at relatively high temperatures. The assumption that the temperature/PLD curve is the same for shallow- and deep-water species is untested for this group and, based on observations in echinoderms and other phyla, may be unwarranted (Young, unpublished data). It was also assumed that dispersal occurred at approximately the same depth as where the adults are found. The observed dispersal kernels were likely too small to maintain connectivity among known populations within a single generation, suggesting the existence of additional undiscovered metapopulations that serve as stepping stones. The accuracy of the biological parameters used is questionable in the absence of empirical data, but because the authors intentionally overestimated dispersal by adding in a pre-larval dispersal phase of 50 days, the major conclusion may be robust.

A recent study used Lagrangian (LTRANS) modeling with regional ocean models system (ROMS) to predict dispersal trajectories of larvae with known PLD, either obtained from larval rearing studies or estimated indirectly from other types of biological data (Young et al., 2012). Dispersal trajectories were estimated for seven cold seep and non-seep species at each of two depths, originating from known adult locations off Barbados, in the Tongue of the Ocean Bahamas, and at seeps in the Gulf of Mexico. Planktonic larval durations ranged from 21 days in cold-seep tubeworms (Lamellibrachia luymesi) to nearly 2 years in bipinnaria larvae of the asteroid Sclerasterias tanneri. For those species with long PLDs, the models showed significantly greater dispersal at $100 \mathrm{~m}$ depth than at $500 \mathrm{~m}$ depth, although the actual ontogenetic movements are unknown for all species. For some species, simulations were run more than once a year, revealing highly significant temporal effects in dispersal distance and underscoring the importance of spawning time. Data on PLD had been measured for two Bahamian echinoids, Stylocidaris lineata and Cidaris blakei (Bennett et al., 2012), and an extended larval life had been documented for the sea star, which provided a conservative estimate of dispersal time. PLD also had been estimated for the tubeworm (Young et al., 1996) on the basis of larval rearing. For the other species, PLD had to be estimated from indirect methods. Based on data on the timing of spawning and seasonal recruitment, and on in situ growth rates of juveniles of Bathymodiolus childressi (Arellano and Young, 2009), settlement times of individuals were back-calculated. The number of 
days since the previous spawning peak to settlement was then determined as the PLD. A similar method was used for the sipunculan Phascolosoma turnerae, known to have a strongly seasonal spawning peak and for which a growth curve had been generated for laboratory-reared juveniles (Rice et al., 2012). Two species of seep molluscs, Bathymodiolus childressi and Bathynerita naticoidea, were collected in the water column during some seasons of the year. Because gametogenic cycles had already been documented for both species, it was possible to infer the approximate ages of the plankton-collected larvae to assist with the estimation of PLD.

The study of Young et al. (2012) demonstrates the value of incorporating various types of biological measurements into the estimation of dispersal distances. A major shortfall of this and all other deep-sea dispersal models is the absence of information on dispersal depth as determined by actual vertical distributions in the plankton (Arellano et al., 2014), or estimated by swimming speed, egg buoyancy, direction of swimming, and physiological tolerances.

\section{MAIN DATA GAPS FOR ESTIMATING CONNECTIVITY IN THE DEEP SEA}

Estimating connectivity in marine ecosystems requires the understanding of the biological and physical processes regulating larval dispersal, settlement and recruitment, which is hindered by the small size of larvae coupled with the vast and complex fluid environment. In the deep sea, the problem is magnified because of inherent barriers of accessibility and sampling constraints. Biophysical modeling approaches, an established technique in marine connectivity research, which incorporate key physical dynamics and biological traits, provide a partial solution to this problem. In the deep sea, however, knowledge gaps in both the physical and biological components are delaying the effective use of finely tuned biophysical models.

The physical components of biophysical models are limited by scale and computational capacity. Large scale processes are well understood and parameterized within model equations, but submesoscale ocean physics is an ongoing area of research. In any case, the phenomena at the small scales relevant to a larva are prohibitively expensive to parameterize within a large spatial scale model. For this reason, a sub-gridscale parameterisation is usually considered an adequate enough approximation for most purposes although this is difficult to estimate in itself. There are additional conflicts of resolution, such as poorly represented topography, and consequential flow modifications, that result from low resolution in bathymetry data. The best high-resolution models rely upon high quality bathymetry which is costly to acquire over large spatial scales, particularly at great depth and distance from shore. Accurate model performance requires the assimilation of and validation by high resolution observational data over large temporal and spatial scales.

Vertical velocity remains the most elusive component of both observed and modeled velocity fields, often reduced to secondary calculation in line with the conservation of energy. Without improved understanding of vertical velocities, the potential for passive vertical migration of larvae also remains elusive. In the end, numerical models should be taken for what they are-simplified approximations of reality offered as a best guess of average hydrographic conditions in the area concerned.

Biological processes that control larval dispersal include the reproductive effort of adults, which determines the timing and number of larvae in the water column, and larval development and behavior. Both these components determine how larvae interact with the oceanic circulation and influence the timing, distance and trajectory of larvae among habitats. Reproductive biology has only been studied for a small fraction of deep-sea species and most of the utilized knowledge on parental investment, egg size and fecundity has been extrapolated from a limited number of samples. Because time-series analyses are rare, measurements on reproductive synchrony and periodicity remains elusive for most deep-sea species. As a result, information on the initial factors controlling larval dispersal, "how many" and "when" larvae enter the water column is largely unavailable.

"How long" larvae spend in the water column is defined by the planktonic larval duration (PLD), a fundamental parameter in dispersal models that is unknown for most deep-sea species and highly variable among those for which it has been estimated. One of the biggest obstacles in acquiring accurate PLD estimates is the difficulty in culturing embryos and larvae in the laboratory. In addition, it remains difficult to assess whether and how pressure and temperature conditions may affect PLDs determined in culture. Studies on early life-history stages are scarce and hampered by sampling difficulties and the general lack of facilities available for long-term maintenance under appropriate conditions.

Lastly, "where" larvae are positioned in the water column is largely determined by their swimming behavior. Most larvae are poor horizontal swimmers, but they can alter their vertical positions actively through vertical swimming and/or passively through differential buoyancy; for deep-sea larvae, changes in vertical position may result in major changes in temperature and pressure, in turn resulting in major consequences in terms metabolic and feeding rates, and other vital processes. Further, because of the vertical structure in current velocity different dispersal pathways will also be affected. Ontogenetic changes in anatomical features can indirectly affect larval behavior, motility (speed) within the water column and nutritional reserves (or feeding regime), in turn influencing vertical positioning. However, detailed larval development characterization has only been achieved for few deep-sea species. Larval behavior and development studies are not only constrained by the difficulty in rearing deep-sea larvae in the laboratory, but also by the difficulty in identifying field collected larvae.

Recent technological advances can help expand our knowledge of reproductive and larval biology for deep-sea species. For example, increasing availability and development of new technologies, including pressure and temperature-controlled sampling vessels and holding facilities (e.g., Pradillon et al., 2004; Mestre et al., 2009, 2013; Ravaux et al., 2013) can facilitate the quantification of PLD and swimming behavior. Moreover, the development of sampling systems associated with larval identification by highthroughput molecular techniques allows direct observation of distribution of deep-sea larvae in the water column.

While many gaps exist in our ability to collect empirical data and use predictive models on the factors that regulate dispersal in 
the deep sea, anthropogenic pressure on this habitat for resource extraction is rapidly increasing. For most of the deep-sea regions currently under threat of major disturbances associated with fishing and mining, our limited understanding of the resident species and communities and the mechanism that regulate them can compromise our ability to manage them sustainably. Despite the cost in filling our knowledge gaps, there is an urgent need to do so.

\section{SUPPLEMENTARY MATERIAL}

The Supplementary Material for this article can be found online at: http://www.frontiersin.org/journal/10.3389/fmars.2015. 00006/abstract

\section{REFERENCES}

Ardron, J., Arnaud-Haond, S., Beaudoin, Y., Bezaury, J., Billet, D., Boland, G., et al. (2011). Environmental Management of Deep-Sea Chemosynthetic Ecosystems: Justification of and Considerations for a Spatially Based Approach. Technical Report of the International Seabed Authority. Avalible online at: https://hal. archives-ouvertes.fr/hal-00667838

Arellano, S. M., Van Gaest, A. L., Johnson, S. B., Vrijenhoek, R. C., and Young, C. M. (2014). Larvae from deep-sea methane seeps disperse in surface waters. Proc. R. Soc. B 281:20133276. doi: 10.1098/rspb.2013.3276

Arellano, S. M., and Young, C. M. (2009). Spawning, development, and the duration of larval life in a deep-sea cold-seep mussel. Biol. Bull. 216, 149-162.

Ayata, S.-D., Lazure, P., and Thiébaut, É. (2010). How does the connectivity between populations mediate range limits of marine invertebrates? A case study of larval dispersal between the Bay of Biscay and the English Channel (North-East Atlantic). Progr. Oceanogr. 87, 18-36. doi: 10.1016/j.pocean.2010. 09.022

Bailey, D. M., Collins, M. A., Gordon, J. D. M., Zuur, A. F., and Priede, I. G. (2009). Long-term changes in deep-water fish populations in the northeast Atlantic: a deeper reaching effect of fisheries? Proc. Royal Soc. B 276, 1965-1969. doi: 10.1098/rspb.2009.0098

Bennett, K. C., Young, C. M., and Emlet, R. B. (2012). Larval development and metamorphosis of the deep-sea cidaroid urchin Cidaris blakei. Biol. Bull. 222, 105-117.

Berg, H. C. (1993). Random Walks in Biology. Princeton, NJ: Princeton University Press.

Bidegain, G., Bárcena, J. F., García, A., and Juanes, J. A. (2013). LARVAHS: predicting clam larval dispersal and recruitment using habitat suitability-based particle tracking model. Ecol. Modell. 268, 78-92. doi: 10.1016/j.ecolmodel.2013.07.020

Blanke, B., Bonhommeau, S., Grima, N., and Drillet, Y. (2012). Sensitivity of advective transfer times across the North Atlantic Ocean to the temporal and spatial resolution of model velocity data: implication for European eel larval transport. Dyn. Atmos. Oceans 55-56, 22-44. doi: 10.1016/j.dynatmoce.2012.04.003

Boschen, R. E., Rowden, A. A., Clark, M. R., and Gardner, J. P. A. (2013). Mining of deep-sea seafloor massive sulfides: a review of the deposits, their benthic communities, impacts from mining, regulatory frameworks and management strategies. Ocean Coast. Manage. 84, 54-67. doi: 10.1016/j.ocecoaman.2013.07.005

Brickman, D., Ådlandsvik, B., Thygesen, U., Parada, C., Rose, K., Hermann, A., et al. (2009). "Particle tracking," in Manual of Recommended Practices For Modelling Physical-Biological Interactions During Fish Early Life, eds E. W. North, A. Gallego, and P. Petitgas (Copenhagen: International Council for the Exploration of the Sea), 3-8.

Brink, K. H. (1995). Tidal and lower frequency currents above Fieberling Guyot. J. Geophys. Res. 100, 10817-10832. doi: 10.1029/95JC00998

Brooke, S. D., and Young, C. M. (2009). Where do the embryos of Riftia pachyptila develop? Pressure tolerances, temperature tolerances, and buoyancy during prolonged embryonic dispersal. Deep-Sea Res. Pt II 56, 1599-1606. doi: 10.1016/j.dsr2.2009.05.003

Burgess, S. C., Nickols, K. J., Griesemer, C. D., Barnett, L. A. K., Dedrick, A. G., Satterthwaite, E. V., et al. (2014). Beyond connectivity: how empirical methods can quantify population persistence to improve marine protected-area design. Ecol. Appl. 24, 257-270. doi: 10.1890/13-0710.1
Butler, M. J. B., Paris, C. B., Goldstein, J. S., Matsuda, H., and Cowen, R. K. (2011). Behavior constrains the dispersal of long-lived spiny lobster larvae. Mar. Ecol. Prog. Ser. 422, 223-237. doi: 10.3354/meps08878

Cannon, G. A., and Pashinski, D. J. (1997). Variations in mean currents affecting hydrothermal plumes on the Juan de Fuca Ridge. J. Geophys. Res. 102, 24965-24976. doi: 10.1029/97JC01910

Carr, S. D., Capet, X. J., McWilliams, J. C., Pennington, J. T., and Chavez, F. P. (2008). The influence of diel vertical migration on zooplankton transport and recruitment in an upwelling region: estimates from a coupled behavioralphysical model. Fish. Oceanogr. 17, 1-15. doi: 10.1111/j.1365-2419.2007.00447.x

Carson, H. S., Lopez-Duarte, P. C., Rasmussen, L., Wang, D., and Levin, L. A. (2010). Reproductive timing alters population connectivity in marine metapopulations. Curr. Biol. 20, 1926-1931. doi: 10.1016/j.cub.2010.09.057

CBD. (2007). Expert Workshop on Ecological Criteria and Biogeographic Classification Systems for Marine Areas in Need of Protection. UNEP/CBD/EWS.MPA/1/2.

Chevaldonné, P., Jollivet, D., Vangriesheim, A., and Desbruyères, D. (1997). Hydrothermal-vent alvinellid polychaete dispersal in the Eastern Pacific. 1. Influence of vent site distribution, bottom currents, and biological patterns. Limnol. Oceanogr. 42, 67-80.

Clark, M. R., Rowden, A. A., Schlacher, T. A., Guinotte, J., Dunstan, P. K., Williams, A., et al. (2014). Identifying ecologically or biologically significant areas (EBSA): a systematic method and its application to seamounts in the South Pacific Ocean. Ocean Coast. Manage. 91, 65-79. doi: 10.1016/j.ocecoaman.2014.01.016

Corell, H., Moksnes, P., Engqvist, A., Döös, K., and Jonsson, P. R. (2012). Depth distribution of larvae critically affects their dispersal and the efficiency of marine protected areas. Mar. Ecol. Prog. Ser. 467, 29-46. doi: 10.3354/meps09963

Cowen, R., Gawarkiewicz, G., Pineda, J., Thorrold, S., and Werner, F. (2007). Population connectivity in marine systems: an overview. Oceanography 20, 14-21. doi: 10.5670/oceanog.2007.26

Cowen, R. K., Lwiza, K. M. M., Sponaugle, S., Paris, C. B., and Olson, D. B. (2000). Connectivity of marine populations: open or closed? Science 287, 857-859. doi: 10.1126/science.287.5454.857

Cowen, R. K., Paris, C. B., and Srinivasan, A. (2006). Scaling of connectivity in marine populations. Science 311, 522-527. doi: 10.1126/science.1122039

Cowen, R. K., and Sponaugle, S. (2009). Larval dispersal and marine population connectivity. Annu. Rev. Marine. Sci. 1, 443-466. doi: 10.1146/annurev.marine.010908.163757

Danovaro, R., Snelgrove, P. V. R., and Tyler, P. (2014). Challenging the paradigms of deep-sea ecology. Trends Ecol. Evol. 29, 465-475. doi: 10.1016/j.tree.2014.06.002

Domingues, C. P., Nolasco, R., Dubert, J., and Queiroga, H. (2012). Modelderived dispersal pathways from multiple source populations explain variability of invertebrate larval supply. PLOS ONE 7:e35794. doi: 10.1371/journal.pone.0035794

Drake, P. T., Edwards, C. A., Morgan, S. G., and Dever, E. P. (2013). Influence of larval behavior on transport and population connectivity in a realistic simulation of the California Current System. J. Mar. Res. 71, 317-350. doi: $10.1357 / 002224013808877099$

Eckert, G. L. (2003). Effects of the planktonic period on marine population fluctuations. Ecology 84, 372-383. doi: 10.1890/0012-9658(2003)084[0372:EOTPP $\mathrm{O}] 2.0 . \mathrm{CO} ; 2$

Fiksen, Ø., Jørgensen, C., Kristiansen, T., Vikebø, F., and Huse, G. (2007). Linking behavioural ecology and oceanography: larval behaviour determines growth, mortality and dispersal. Mar. Ecol. Prog. Ser. 347, 195-205. doi: 10.3354/meps06978

Fisher, C. R., Hsing, P.-Y., Kaiser, C. L., Yoerger, D. R., Roberts, H. H., et al. (2014). Footprint of Deepwater Horizon blowout impact to deepwater coral communities. Proc. Natl. Acad. Sci. U.S.A. 11, 11744-11749. doi: 10.1073/pnas.1403492111

Fossette, S., Putman, N. F., Lohmann, K. J., Marsh, R., and Hays, G. C. (2012). A biologist's guide to assessing ocean currents: a review. Mar. Ecol. Prog. Ser. 457, 285-301. doi: 10.3354/meps09581

Foster, N. L., Foggo, A., and Howell, K. L. (2013). Using species-area relationships to inform baseline conservation targets for the deep North East Atlantic. PLoS ONE 8:e58941. doi: 10.1371/journal.pone.0058941

Foster, N. L., Paris, C. B., Kool, J. T., Baums, I. B., Stevens, J. R., Sanchez, J. A., et al. (2012). Connectivity of Caribbean coral populations: complementary insights from empirical and modelled gene flow. Mol. Ecol. 21, 1143-1157. doi: 10.1111/j.1365-294X.2012.05455.x 
Gaines, S. D., Gaylord, B., and Largier, J. L. (2003). Avoiding current oversights in marine reserve design. Ecol. Appl. 13, 32-46. doi: 10.1890/10510761(2003)013[0032:ACOIMR]2.0.CO;2

Gilbert, C. S., Gentleman, W. C., Johnson, C. L., DiBacco, C., Pringle, J. M., and Chen, C. (2010). Modelling dispersal of sea scallop (Placopecten magellanicus) larvae on Georges Bank: the influence of depth-distribution, planktonic duration and spawning seasonality. Progr. Oceanogr. 87, 37-48. doi: 10.1016/j.pocean.2010.09.021

Grassle, J., and Maciolek, N. (1992). Deep-sea species richness?: regional and local diversity estimates from quantitative bottom samples. Am. Nat. 139, 313-341.

Guizien, K., Belharet, M., Marsaleix, P., and Guarini, J. M. (2012). Using larval dispersal simulations for marine protected area design: application to the Gulf of Lions (northwest Mediterranean). Limnol. Oceanogr. 57, 1099-1112. doi: 10.4319/lo.2012.57.4.1099

Halpern, B. S. (2003). The impact of marine reserves: do reserves work and does reserve size matter? Ecol. Appl. 13, 117-137. doi: 10.1890/10510761(2003)013[0117:TIOMRD]2.0.CO;2

Hastings, A., and Botsford, L. W. (2003). Comparing designs of marine reserves for fisheries and for biodiversity. Ecol. Appl. 13, 65-70. doi: 10.1890/10510761(2003)013[0065:CDOMRF]2.0.CO;2

Hautala, S. L., and Riser, S. C. (1993). A nonconservative $\beta$-spiral determination of the deep circulation in the Eastern South Pacific. J. Phys. Oceanogr. 23, 1975-2000. doi: 10.1175/1520-0485(1993)023<1975:ANSDOT > 2.0.CO;2

Hogg, N. G., and Owens, W. B. (1999). Direct measurement of the deep circulation within the Brazil Basin. Deep Sea Res. Part II 46, 335-353. doi: 10.1016/S09670645(98)00097-6

Howell, K. L. (2010). A benthic classification system to aid in the implementation of marine protected area networks in the deep/high seas of the NE Atlantic. Biol. Conserv. 143, 1041-1056. doi: 10.1016/j.biocon.2010.02.001

Howell, K. L., Davies, J. S., and Narayanaswamy, B. E. (2010). Identifying deep-sea megafaunal epibenthic assemblages for use in habitat mapping and marine protected area network design. J Mar Biol Ass UK 90, 33-68. doi: $10.1017 /$ S0025315409991299

ISBA. (2011). Environmental Management Plan for the Clarion-Clipperton Zone. ISBA/17/LTC/7.

ISBA. (2014). Report of the Secretary-General of the International Seabed Authority under article 166, paragraph 4, of the United Nations Convention on the Law of the Sea. ISBA/20/A/2.

Jackson, E. L., Davies, A. J., Howell, K. L., Kershaw, P. J., and Hall-Spencer, J. M. (2014). Future-proofing marine protected area networks for cold water coral reefs. ICES J. Mar. Sci. 71, 2621-2629. doi: 10.1093/icesjms/fsu099

Jackson, G. A., and Strathmann, R. R. (1981). Larval mortality from offshore mixing as a link between precompetent and competent periods of development. Amer. Nat. 118, 16-26. doi: 10.1086/283797

Jackson, P. R., Ledwell, J. R., and Thurnherr, A. M. (2010). Dispersion of a tracer on the East Pacific Rise $\left(9^{\circ} \mathrm{N}\right.$ to $\left.10^{\circ} \mathrm{N}\right)$, including the influence of hydrothermal plumes. Deep Sea Res. Part I 57, 37-52. doi: 10.1016/j.dsr.2009.10.011

Jahnke, R. A. (1996). The global ocean flux of particulate organic carbon: areal distribution and magnitude. Global Biogeochem. Cycles 10, 71-88. doi: 10.1029/95GB03525

Kool, J. T., Moilanen, A., and Treml, E. A. (2013). Population connectivity: recent advances and new perspectives. Landsc. Ecol. 28, 165-185. doi: 10.1007/s10980012-9819-z

Koslow, J. A., Boehlert, G. W., Gordon, J. D. M., Haedrich, R. L., Lorance, P., and Parin, N. (2000). Continental slope and deep-sea fisheries: implications for a fragile ecosystem. ICES J. Mar. Sci. 57, 548-557. doi: 10.1006/jmsc.2000.0722

Kough, A. S., Paris, C. B., and Butler, I. V., M. J. (2013). Larval connectivity and the international management of fisheries. PLOS ONE 8:e64970. doi: 10.1371/journal.pone.0064970

Lacroix, G., McCloghrie, P., Huret, M., and North, E. (2009). "Hydrodynamic Models," in Manual of Recommended Practices for Modelling Physical-Biological Interactions During Fish Early Life, eds E. W. North, A. Gallego, and P. Petitgas (Copenhagen: International Council for the Exploration of the Sea), 9-19.

Lavelle, J. W., Thurnherr, A. M., Ledwell, J. R., McGillicuddy, D. J., and Mullineaux, L. S. (2010). Deep ocean circulation and transport where the East Pacific Rise at $9-10^{\circ} \mathrm{N}$ meets the Lamont seamount chain. J. Geophys. Res. 115, C12073. doi: 10.1029/2010JC006426
Ledwell, J. R., St. Laurent, L. C., Girton, J. B., and Toole, J. M. (2011). Diapycnal mixing in the Antarctic circumpolar current. J. Phys. Oceanogr. 41, 241-246. doi: 10.1175/2010JPO4557.1

Ledwell, J. R., Montgomery, E. T., Polzin, K. L., Laurent, L. C. S., Schmitt, R. W., and Toole, J. M. (2000). Evidence for enhanced mixing over rough topography in the abyssal ocean. Nature 403, 179-182. doi: 10.1038/350 03164

Ledwell, J. R., and Watson, A. J. (1991). The Santa Monica Basin tracer experiment: a study of diapycnal and isopycnal mixing. J. Geophys. Res. 96, 8695-8718. doi: 10.1029/91JC00102

Ledwell, J. R., Watson, A. J., and Law, C. S. (1993). Evidence for slow mixing across the pycnocline from an open-ocean tracer-release experiment. Nature 364, 701-703. doi: 10.1038/364701a0

Lett, C., Ayata, S.-D., Huret, M., and Irisson, J.-O. (2010). Biophysical modelling to investigate the effects of climate change on marine population dispersal and connectivity. Progr. Oceanogr. 87, 106-113. doi: 10.1016/j.pocean.2010.09.005

Levin, L. A. (2006). Recent progress in understanding larval dispersal: new directions and digressions. Integr. Comp. Biol. 46, 282-297. doi: 10.1093/icb/icj024

Liggins, L., Treml, E. A., and Riginos, C. (2013). Taking the plunge: an introduction to undertaking seascape genetic studies and using biophysical models. Geography. Compass 7, 173-196. doi: 10.1111/gec3.12031

Marsh, A. G., Mullineaux, L. S., Young, C. M., and Manahan, D. T. (2001). Larval dispersal potential of the tubeworm Riftia pachyptila at deep-sea hydrothermal vents. Nature 411, 77-80. doi: 10.1038/35075063

Martins, R. S., Roberts, M. J., Chang, N., Verley, P., Moloney, C. L., and Vidal, E. A. G. (2010). Effect of yolk utilization on the specific gravity of chokka squid (Loligo reynaudii) paralarvae: implications for dispersal on the Agulhas Bank, South Africa. ICES J. Mar. Sci. 67, 1323-1335. doi: 10.1093/icesjms/fsq098

McClain, C. R., and Hardy, S. M. (2010). The dynamics of biogeographic ranges in the deep sea. Proc. R. Soc. B. 277, 3533-3546. doi: 10.1098/rspb.2010.1057

McGillicuddy, D. J. Jr., Lavelle, J. W., Thurnherr, A. M., Kosnyrev, V. K., and Mullineaux, L. S. (2010). Larval dispersion along an axially symmetric midocean ridge. Deep Sea Res. Part I 57, 880-892. doi: 10.1016/j.dsr.2010.04.003

Mengerink, K. J., Van Dover, C. L., Ardron, J., Baker, M., Escobar Briones, E., Gjerde, K., et al. (2014). A call for deep-ocean stewardship. Science 344, 696-698. doi: $10.1126 /$ science. 1251458

Mercier, A., Sewell, M. A., and Hamel, J.-F. (2013). Pelagic propagule duration and developmental mode: reassessment of a fading link. Glob. Ecol. Biogeogr. 22, 517-530. doi: 10.1111/geb.12018

Mestre, N. C., Brown, A., and Thatje, S. (2013). Temperature and pressure tolerance of larvae of Crepidula fornicata suggest thermal limitation of bathymetric range. Mar. Biol. 160, 743-750. doi: 10.1007/s00227-012-2128-x

Mestre, N. C., Thatje, S., and Tyler, P. A. (2009). The ocean is not deep enough: pressure tolerances during early ontogeny of the blue mussel Mytilus edulis. Proc. R. Soc. B 276, 717-726. doi: 10.1098/rspb.2008.1376

Metaxas, A., and Kelly, N. E. (2010). Do larval supply and recruitment vary among chemosynthetic environments of the deep sea? PLoS ONE 5:e11646. doi: 10.1371/journal.pone.0011646

Metaxas, A., and Saunders, M. (2009). Quantifying the "Bio-" components in biophysical models of larval transport in marine benthic invertebrates: advances and pitfalls. Biol. Bull. 216, 257-272.

Mitarai, S., Siegel, D. A., Watson, J. R., Dong, C., and McWilliams, J. C. (2009). Quantifying connectivity in the coastal ocean with application to the Southern California Bight. J. Geophys. Res. 114, C10026. doi: 10.1029/2008JC005166

Mullineaux, L. S., McGillicuddy, D. J. Jr., and Mills, S. W. (2013). Active positioning of vent larvae at a mid-ocean ridge. Deep Sea Res. Part I 92, 46-57. doi: 10.1016/j.dsr2.2013.03.032

Mullineaux, L. S., Speer, K. G., Thurnherr, A. M., Maltrud, M. E., and Vangriesheim, A. (2002). Implications of cross-axis flow for larval dispersal along mid-ocean ridges. Cah. Biol. Mar. 43, 281-284.

Nakajima, R., Yamakita, T., Watanabe, H., Fujikura, K., Tanaka, K., Yamamoto, H., et al. (2014). Species richness and community structure of benthic macrofauna and megafauna in the deep-sea chemosynthetic ecosystems around the Japanese archipelago: an attempt to identify priority areas for conservation. Divers. Distrib. 20, 1160-1172. doi: 10.1111/ddi.12204

NEAFC. (2011). Consolidated text of all NEAFC recommendations on regulating Bottom Fishing. Available online at: http://www.neafc.org/system/files/consolidated_bottomfishing_regulations.pdf 
Nicolle, A., Dumas, F., Foveau, A., Foucher, E., and Thiébaut, E. (2013). Modelling larval dispersal of the king scallop (Pecten maximus) in the English Channel: examples from the bay of Saint-Brieuc and the bay of Seine. Ocean Dynam. 63, 661-678. doi: 10.1007/s10236-013-0617-1

Nolasco, R., Dubert, J., Domingues, C. P., Pires, A. C., and Queiroga, H. (2013). Model-derived connectivity patterns along the western Iberian Peninsula: asymmetrical larval flow and source-sink cell. Mar. Ecol. Prog. Ser. 485, 123-142. doi: $10.3354 /$ meps 10324

North, E. W., Gallego, A., and Petitgas, P. (2009). Manual of Recommended Practices for Modelling Physical-biological Interactions During Fish Early Life. Copenhagen: International Council for the Exploration of the Sea.

OSPAR. (2003). "OSPAR convention for the protection of the marine environment of the Northeast Atlantic," in Meeting of the OSPAR Commission (Bremen). Recommendation 2003/3 on a Network of Marine Protected Areas. OSPAR 03/17/1-E; Annex 9.

Paris, C. B., Chérubin, L. M., and Cowen, R. K. (2007). Surfing, spinning, or diving from reef to reef: effects on population connectivity. Mar. Ecol. Prog. Ser. 347, 285-300. doi: 10.3354/meps06985

Paris, C. B., and Cowen, R. K. (2004). Direct evidence of a biophysical retention mechanism for coral reef fish larvae. Limnol. Oceanogr. 49, 1964-1979. doi: 10.4319/lo.2004.49.6.1964

Paris, C., Irisson, J.-O., Lacroix, G., Fiksen, Ø., Leis, J., and Mullon, C. (2009). "Connectivity," in Manual of Recommended Practices for Modelling PhysicalBiological Interactions During Fish Early Life, eds. E. W. North, A. Gallego, and P. Petitgas (Copenhagen: International Council for the Exploration of the Sea).

Paulay, G., and Meyer, C. (2006). Dispersal and divergence across the greatest ocean region: do larvae matter? Integr. Comp. Biol. 46, 269-281. doi: 10.1093/icb/icj027

Pradillon, F., Le Bris, N., Shillito, B., Young, C., and Gaill, F. (2005). Influence of environmental conditions on early development of the hydrothermal vent polychaete Alvinella pompejana. J. Exp. Biol. 208, 1551-1561. doi: 10.1242/jeb.01567

Pradillon, F., Shillito, B., Chervin, J. C., Hamel, G., and Gaill, F. (2004). Pressure vessels for in vivo studies of deep-sea fauna. High. Press. Res. 24, 237-246. doi: 10.1080/08957950410001699818

Pradillon, F., Shillito, B., Young, C., and Gaill, F. (2001). Developmental arrest in vent worm embryos. Nature 413, 698-699. doi: 10.1038/35099674

Proehl, J. A., Lynch, D. R., McGillicuddy, D. J. Jr., and Ledwell, J. R. (2005). Modeling turbulent dispersion on the North Flank of Georges bank using lagrangian particle methods. Cont. Shelf Res. 25, 875-900. doi: 10.1016/j.csr.2004.09.022

Putman, N. F., and He, R. (2013). Tracking the long-distance dispersal of marine organisms: sensitivity to ocean model resolution. J. R. Soc. Interface 10:20120979. doi: 10.1098/rsif.2012.0979

Ramirez-Llodra, E., Brandt, A., Danovaro, R., De Mol, B., Escobar, E., German, C. R., et al. (2010). Deep, diverse and definitely different: unique attributes of the world's largest ecosystem. Biogeosciences 7, 2851-2899. doi: 10.5194/bg-7-28512010

Ramirez-Llodra, E., Tyler, P. A., Baker, M. C., Bergstad, O. A., Clark, M. R., Escobar, E., et al. (2011). Man and the last great wilderness: human impact on the Deep Sea. PLoS ONE 6:e22588. doi: 10.1371/journal.pone.0022588

Ravaux, J., Hamel, G., Zbinden, M., Tasiemski, A. A., Boutet, I., Léger, N., et al. (2013). Thermal limit for metazoan life in question: in vivo heat tolerance of the pompeii worm. PLoS ONE 8:e64074. doi: 10.1371/journal.pone.0064074

Rengstorf, A. M., Yesson, C., Brown, C., and Grehan, A. J. (2013). High-resolution habitat suitability modelling can improve conservation of vulnerable marine ecosystems in the deep sea. J. Biogeogr. 40, 1702-1714. doi: 10.1111/jbi. 12123

Rice, M. E., Reichardt, H. F., Piraino, J., and Young, C. M. (2012). Reproduction, development, growth, and the length of larval life of Phascolosoma turnerae, a wood-dwelling deep-sea sipunculan. Invertebr. Biol. 131, 204-215. doi: 10.1111/j.1744-7410.2012.00267.x

Roberts, C. M. (1997). Connectivity and management of caribbean coral reefs. Science 278, 1454-1457.

Ross, R. E., and Howell, K. L. (2013). Use of predictive habitat modelling to assess the distribution and extent of the current protection of listed' deep-sea habitats. Divers Distrib. 19, 433-445. doi: 10.1111/ddi.12010

Sale, P. F., Cowen, R. K., Danilowicz, B. S., Jones, G. P., Kritzer, J. P., Lindeman, K. C., et al. (2005). Critical science gaps impede use of no-take fishery reserves. Trends Ecol. Evol. 20, 74-80. doi: 10.1016/j.tree.2004.11.007
Schlacher, T. A., Baco, A. R., Rowden, A. A., O’Hara, T. D., Clark, M. R., Kelley, C., et al. (2014). Seamount benthos in a cobalt-rich crust region of the central Pacific: conservation challenges for future seabed mining. Divers. Distrib. 20, 491-502. doi: 10.1111/ddi.12142

Selkoe, K. A., and Toonen, R. J. (2011). Marine connectivity: a new look at pelagic larval duration and genetic metrics of dispersal. Mar. Ecol. Prog. Ser. 436, 291-305. doi: 10.3354/meps09238

Shanks, A. L. (2009). Pelagic larval duration and dispersal distance revisited. Biol. Bull. 216, 373-385.

Shanks, A. L., Grantham, B. A., and Carr, M. H. (2003). Propagule dispersal distance and the size and spacing of marine reserves. Ecol. Appl. 13, 159-169. doi: 10.1890/1051-0761(2003)013[0159:PDDATS]2.0.CO;2

Shilling, F. M., and Manahan, D. T. (1994). Energy metabolism and amino acid transport during early development of Antarctic and temperate echinoderms. Biol. Bul. 187, 398-407.

Siegel, D. A., Kinlan, B. P., Gaylord, B., and Gaines, S. D. (2003). Lagrangian descriptions of marine larval dispersion. Mar. Ecol. Prog. Ser. 260, 83-96. doi: $10.3354 /$ meps 260083

Siegel, D. A., Mitarai, S., Costello, C. J., Gaines, S. D., Kendall, B. E., Warner, R. R., et al. (2008). The stochastic nature of larval connectivity among nearshore marine populations. Proc. Natl. Acad. Sci. U.S.A. 105, 8974-8979. doi: 10.1073/pnas.0802544105

Simons, R. D., Siegel, D. A., and Brown, K. S. (2013). Model sensitivity and robustness in the estimation of larval transport: a study of particle tracking parameters. J. Mar. Syst. 119-120, 19-29. doi: 10.1016/j.jmarsys.2013.03.004

Soria, G., Munguía-Vega, A., Marinone, S. G., Moreno-Báez, M., Martínez-Tovar, I., and Cudney-Bueno, R. (2012). Linking bio-oceanography and population genetics to assess larval connectivity. Mar. Ecol. Prog. Ser. 463, 159-175. doi: 10.3354/meps09866

Speer, K. G., Maltrud, M. E., and Thurnherr, A. M. (2003). "A global view of dispersion above the mid-ocean ridge," in Energy and Mass Transfer in Marine Hydrothermal Systems, eds P. E. Halbach, V. Tunnicliffe, and J. R. Hein (Berlin: Dahlem University Press), 287-302.

Sponaugle, S., Cowen, R. K., Shanks, A., Morgan, S. G., Leis, J. M., Pineda, J., et al. (2002). Predicting self-recruitment in marine populations: biophysical correlates and mechanisms. Bull. Mar. Sci. 70, 341-375.

Stahr, F. R., and Sanford, T. B. (1999). Transport and bottom boundary layer observations of the North Atlantic deep western boundary current at the blake outer ridge. Deep Sea Res. Part II 46, 205-243. doi: 10.1016/S0967-0645(98)00101-5

Strathmann, R. R. (2007). Three functionally distinct kinds of pelagic development. Bull. Mar. Sci. 81, 167-179.

Sundelöf, A., and Jonsson, P. R. (2012). Larval dispersal and vertical migration behaviour - a simulation study for short dispersal times. Mar. Ecol. 33, 183-193. doi: 10.1111/j.1439-0485.2011.00485.x

Thorson, G. (1950). Reproductive and larval ecology of marine bottom invertebrates. Biol. Rev. 25, 1-45.

Thorson, G. (1964). Light as an ecological factor in the dispersal and settlement of larvae of marine bottom invertebrates. Ophelia 1, 167-208. doi: 10.1080/00785326.1964.10416277

Thurber, A. R., Sweetman, A. K., Narayanaswamy, B. E., Jones, D. O. B., Ingels, J., and Hansman, R. L. (2014). Ecosystem function and services provided by the deep sea. Biogeosciences 11, 3941-3963. doi: 10.5194/bg-11-3941-2014

Thurnherr, A. M., Ledwell, J. R., Lavelle, J. W., and Mullineaux, L. S. (2011). Hydrography and circulation near the crest of the East Pacific Rise between $9^{\circ}$ and $10^{\circ}$ N. Deep Sea Res. Part I 58, 365-376. doi: 10.1016/j.dsr.2011.01.009

Thurnherr, A. M., and Richards, K. J. (2001). Hydrography and high-temperature heat flux of the Rainbow hydrothermal site $\left(36^{\circ} 14^{\prime} \mathrm{N}\right.$, Mid-Atlantic Ridge). J. Geophys. Res. 106, 9411-9426. doi: 10.1029/2000JC900164

Treml, E. A., and Halpin, P. N. (2012). Marine population connectivity identifies ecological neighbors for conservation planning in the Coral Triangle. Conserv. Lett. 5, 441-449. doi: 10.1111/j.1755-263X.2012.00260.x

Treml, E. A., Halpin, P. N., Urban, D. L., and Pratson, L. F. (2008). Modeling population connectivity by ocean currents, a graph-theoretic approach for marine conservation. Landsc. Ecol. 23, 19-36. doi: 10.1007/s10980-007-9138-y

Treml, E. A., Roberts, J. J., Chao, Y., Halpin, P. N., Possingham, H. P., and Riginos, C. (2012). Reproductive output and duration of the pelagic larval stage determine seascape-wide connectivity of marine populations. Integr. Comp. Biol. 52, 525-537. doi: 10.1093/icb/ics101 
Tyler, P. A. (2003). "Introduction," in Ecosystems of the Deep Oceans, Vol. 28. of Ecosystems of the World, ed P. A. Tyler (Amsterdam: Elsevier), 1-3.

Tyler, P. A., and Young, C. M. (1999). Reproduction and dispersal at vents and cold seeps. J. Mar. Biol. Assoc. UK 79, 193-208.

Van Dover, C. L., Smith, C. R., Ardron, J., Dunn, D., Gjerde, K., Levin, L., et al. (2012). Designating networks of chemosynthetic ecosystem reserves in the deep sea. Mar. Policy 36, 378-381. doi: 10.1016/j.marpol.2011.07.002

Watson, J. R., Mitarai, S., Siegel, D. A., Caselle, J. E., Dong, C., and McWilliams, J. C. (2010). Realized and potential larval connectivity in the Southern California Bight. Mar. Ecol. Prog. Ser. 401, 31-48. doi: 10.3354/ meps 08376

Wedding, L. M., Friedlander, A. M., Kittinger, J. N., Watling, L., Gaines, S. D., Bennett, M., et al. (2013). From principles to practice: a spatial approach to systematic conservation planning in the deep sea. Proc. R. Soc. B 280:20131684. doi: $10.1098 / \mathrm{rspb} .2013 .1684$

Weersing, K., and Toonen, R. J. (2009). Population genetics, larval dispersal, and connectivity in marine systems. Mar. Ecol. Prog. Ser. 393, 1-12. doi: $10.3354 /$ meps 08287

Werner, F., Cowen, R., and Paris, C. (2007). Coupled biological and physical models: present capabilities and necessary developments for future studies of population connectivity. Oceanography 20, 54-69. doi: 10.5670/oceanog.2007.29

Yearsley, J. M., and Sigwart, J. D. (2011). Larval transport modelling of deepsea invertebrates can aid the search for undiscovered populations. PLOS ONE 6:e23063. doi: 10.1371/journal.pone.0023063

Young, C. M. (2003). "Reproduction, development and life-history traits," in Ecosystems of the Deep Oceans, Vol. 28. of Ecosystems of the World, ed P. A. Tyler (Amsterdam: Elsevier), 381-426.
Young, C. M., He, R., Emlet, R. B., Li, Y., Qian, H., Arellano, S. M., et al. (2012). Dispersal of deep-sea larvae from the intra-American seas: simulations of trajectories using ocean models. Integr. Comp. Biol. 52, 483-496. doi: 10.1093/icb/ics090

Young, C. M., Vazquez, E., Metaxas, A., and Tyler, P. A. (1996). Embryology of vestimentiferan tube worms from deep-sea methane/sulphide seeps. Nature 381, 514-516. doi: $10.1038 / 381514 a 0$

Conflict of Interest Statement: The authors declare that the research was conducted in the absence of any commercial or financial relationships that could be construed as a potential conflict of interest.

Received: 17 November 2014; accepted: 22 January 2015; published online: 13 February 2015.

Citation: Hilário A, Metaxas A, Gaudron SM, Howell KL, Mercier A, Mestre NC, Ross RE, Thurnherr AM and Young C (2015) Estimating dispersal distance in the deep sea: challenges and applications to marine reserves. Front. Mar. Sci. 2:6. doi: 10.3389/ fmars.2015.00006

This article was submitted to Deep-Sea Environments and Ecology, a section of the journal Frontiers in Marine Science.

Copyright () 2015 Hilário, Metaxas, Gaudron, Howell, Mercier, Mestre, Ross, Thurnherr and Young. This is an open-access article distributed under the terms of the Creative Commons Attribution License (CC BY). The use, distribution or reproduction in other forums is permitted, provided the original author(s) or licensor are credited and that the original publication in this journal is cited, in accordance with accepted academic practice. No use, distribution or reproduction is permitted which does not comply with these terms. 